\title{
FEASIBILITY STUDY OF DEZ ARCH DAM HEIGHTENING BASED ON NONLINEAR NUMERICAL ANALYSIS OF EXISTING DAM
}

\author{
M. A. HARIRI-ARDEBILI ${ }^{1}$, H. MIRZABOZORG ${ }^{2}$
}

\begin{abstract}
The Dez dam was commissioned in 1963 and since sediments accumulated in the reservoir up to an elevation of approximately $15 \mathrm{~m}$ below the intake of the power tunnel. One of the possible measures to improve operation of the reservoir is by heightening of the existing dam. This paper describes the conducted procedure for static and thermal calibration of this $203 \mathrm{~m}$ dam in Iran based on micro geodesies measurements. Also the nonlinear response of existing dam is investigated under maximum credible earthquake ground motions considering joint behavior and mass concrete cracking and safety of dam is evaluated for possible heightening. For thermal calibration of provided numerical model, transient thermal analysis was conducted and results were compared with thermometers records installed in central block. In addition, for static calibration; thermal distribution within dam body, dam self weight, hydrostatic pressure and silt load applied on the 3D finite element model of dam-reservoir-foundation were considered. Results show that the distribution of stresses will be critical within dam for heightening case under seismic loads in MCL.
\end{abstract}

Key words: Arch dam; Numerical model; Nonlinear analysis; Safety evaluation; Load combination.

\section{INTRODUCTION}

Considering irrecoverable consequences of arch dam failure, continuous safety evaluation of these multi-phase structures seems essential especially in high seismicity regions. Evaluation of dam safety for earthquake excitation is an important task not only in design process of a new dam, but also for safety checks of dams already under operation. The periodic assessment and monitoring should organize for old arch dams considering new conditions and updated instructions.

The actual behavior of an arch dam should be evaluated considering various details such as realistic numerical model of dam body, appropriate simulation of environment like as reservoir and foundation rock, considering contraction and peripheral joints, suitable constitutive model for mass concrete and rock, effects of environments actions like thermal loads, dam-foundation-reservoir interaction and so on.

1 Ph.D. Student, Department of Civil Environmental and Architectural Engineering, University of Colorado, Boulder, CO, USA, mohammad.haririardebili@colorado.edu, ECCE 168, UBC 80309-0428, Boulder, CO, USA, Tell: (+1)303-492-7459.

${ }^{2}$ Corresponding author, Ph.D., Assistant Professor, Department of Civil Engineering, K. N. Toosi University of Technology, Tehran, Iran, Mirzabozorg@kntu.ac.ir, 15875-4416, Vali-asr St., Tehran, Iran, Tel: +98(21)8406-4150. 
In the process of safety assessment, several problems may be occurring for engineer/analyzer which has to overcome to them. For example, insufficiency of the capacity of outlets due to the limited availability of hydrological data at the design stage, ageing and deterioration of the materials due to environmental conditions and possible chemical-physical phenomena, limited strength of the structures with reference to seismic loads not considered at the design stage, problems related to the updated in standards and guidelines [1].

The present paper study static, thermal and seismic safety evaluation of the DEZ high arch dam and includes the main features used for calibration of thermal and structural numerical model of dam-foundation-reservoir system. Thermal transient analyses and also structural analyses are performed considering all significant parameters in results. Finally we answer to this question that is DEZ dam safe in the present condition under maximum credible earthquakes and is it strength enough to heightening in order to increasing capacity of reservoir?

\section{Description of DEZ arch DAM}

The DEZ dam is a $203 \mathrm{~m}$ high double curvature arch dam with a peripheral joint separating the dam body from a concrete saddle structure called Pulvino (figure 1) [2]. The dam is located in a narrow gorge at the DEZ River, in the Khuzestan Province in Iran. The Dam was commissioned in 1963 and since then sediments accumulated in the reservoir up to an elevation of approximately $15 \mathrm{~m}$ below the intake of the power tunnel. One of the possible measures to improve operation of the reservoir and to compensate

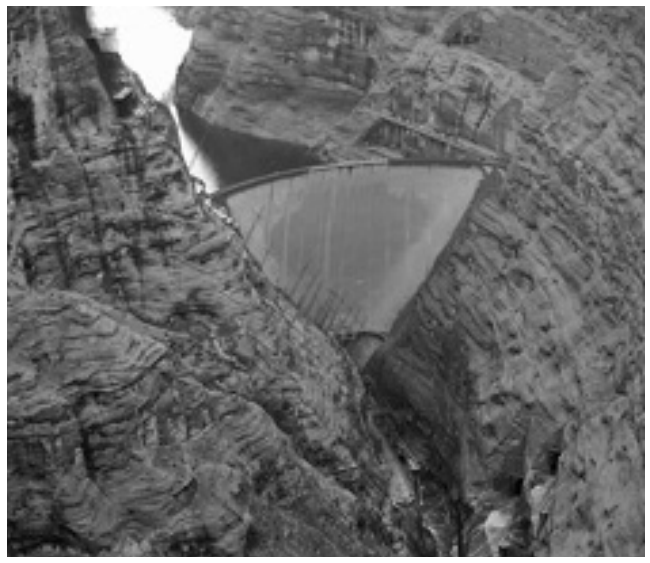

(a)

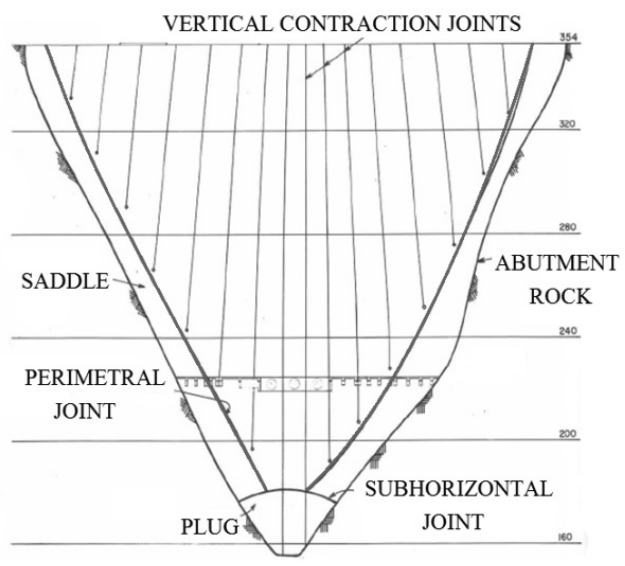

(b)

Fig. 1. DEZ concrete arch dam, (a) General view of dam, river and reservoir, (b) Downstream view of dam body and Pulvino [3]. 
for the loss of storage due to sedimentation is by heightening of the existing dam. General characteristics of DEZ arch dam are summarized in table 1 [3].

At every level, the configuration of the upstream face is a constant radius arc, having a common center with the constant radius arc of the central portion of the downstream face. This results in a constant thickness, at each level, for the central portion of the arch. Towards the abutments, the downstream face follows smaller radii arcs, thereby increasing the arch thickness as the abutments are approached. The central angles of the arches increase gradually from the roadway over the top of the dam to approximately six-tenths of the top of the plug, which is located approximately nine-tenths of the distance down from the top of the roadway. The radii of the arches decrease from top to bottom. The centers of horizontal arches also move upstream. This results in a pronounced downstream overhang of the roadway in central portion of the dam and a general concave appearance when viewed from downstream.

Table 1

Main characteristics of DEZ arch dam

\begin{tabular}{|c|c|}
\hline Maximum height above the foundation & $203.5 \mathrm{~m}$ \\
\hline Crest length & $240 \mathrm{~m}$ \\
\hline Crest thickness & $4.5 \mathrm{~m}$ \\
\hline Base thickness at body/PULVINO & $21 \mathrm{~m} / 28 \mathrm{~m}$ \\
\hline Concrete volume (dam only) & $328000 \mathrm{~m}^{3}$ \\
\hline Concrete volume (dam and PULVINO) & $142000 \mathrm{~m}^{3}$ \\
\hline Crest height & $354 \mathrm{~m}$ as ${ }^{*}$ \\
\hline Normal operational level & $350 \mathrm{~m} \mathrm{asl}$ \\
\hline Minimum operational level & $290 \mathrm{~m} \mathrm{asl}$ \\
\hline Full reservoir capacity & $3350 \mathrm{Mm}^{3}$ \\
\hline
\end{tabular}

* Above sea level

DEZ is categorized as thin arch dams. For the evaluation of the dam's shape the slenderness coefficient according to Kaech and Lombardi [4] is calculated. This factor relates the dam surface to the concrete volume and the height of the dam. The formula reads accordingly:

$$
c=\frac{F^{2}}{V . H}
$$

where $\mathrm{F}$ is the dam surface area, $\mathrm{V}$ is the dam volume and $\mathrm{H}$ is the dam height. From this the slenderness coefficient can be calculated as $c=12.28$ for the dam. The slen- 
derness coefficient alone is not sufficient for the evaluation of a dam's shape since it does not take into account the shape of the valley. The slenderness of a dam can be better evaluated on the basis of the slenderness factor multiplied with the dam's height $(\mathrm{c} \times \mathrm{H})$. Arch dams should remain below 2500. Dams with higher slenderness have an above-average susceptibility to damage [4]. This value is 2422 for DEZ dam which is very close to 2500 . Also it should mention that, the dam body above the concrete saddle is actually more slender than previous status. Figure 2 shows DEZ dam situation among some famous arch dams with a view to slenderness.

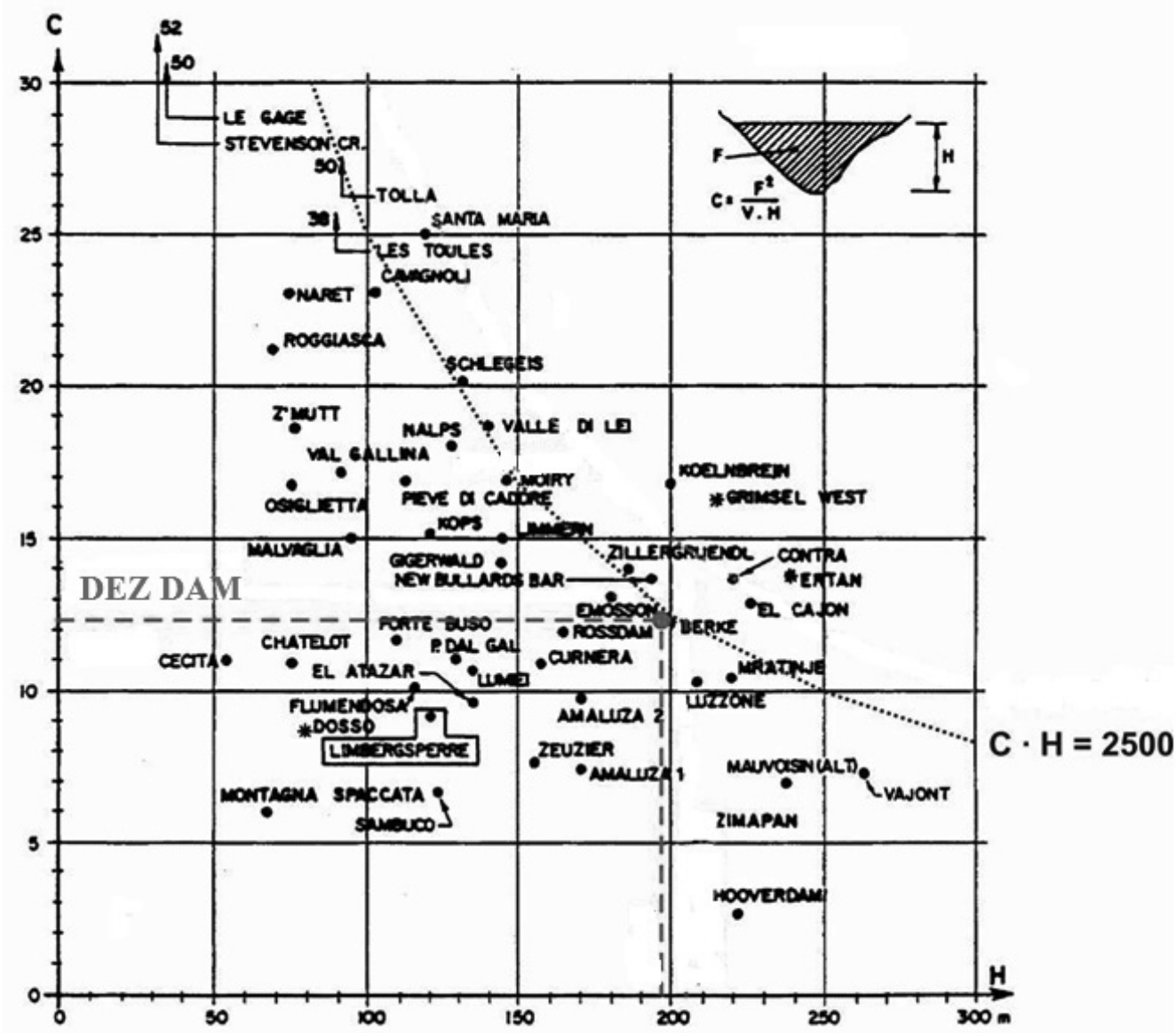

Fig. 2. Slenderness of DEZ arch dam. 


\section{Methodology for SAFEty eVAluation}

Safety evaluation of arch dam should be considered in both static and dynamic conditions. The recommended earthquake loading for seismic evaluation of existing arch dams is maximum credible earthquake (MCE) which is conducted on finite element model of dam in linear elastic (LE) condition [5]. In most cases, Linear Time-History (LTH) analysis coupled with engineering judgment is sufficient to evaluate the safety of an arch dam under seismic loading. If severe damage is indicated, nonlinear dynamic analysis considering details as much as possible to obtain realistic results which are basic for future decisions is required.

In present study, based on analyses conducted by authors on linear finite element model of DEZ dam and estimation of severe damage in both upstream (UP) and downstream (DS) faces in maximum credible level (MCL), Nonlinear Time-History (NLTH) analyses considering effects of contraction and perimetral joints and also nonlinear behavior of mass concrete was utilized for evaluation of dam safety and stability of dam blocks considering possible failure modes.

In the first step, a finite element model of dam was prepared and thermal transient analyses were performed for reveal temperature distribution through the dam thickness. Static and dynamic analyses were conducted for simulated dam-foundation-reservoir system, respectively. It is noteworthy that the calibration of numerical model with data obtained from instruments and site observation were always considered to extract actual results.

\section{Transient thermal analysis}

One of main loads affecting structural behavior of thin arch dams is thermal load. In the current study, thermal version of NSAD-DRI [6] is utilized for conducting transient thermal analyses of DEZ dam. This software is an academic program and is able to account for solar radiation in addition to common boundary conditions which must be applied for transient thermal analysis of arch dams.

\subsection{Appropriate finite ElEMENT MODEL}

A 3D finite element analysis was carried out to investigate temperature distribution within the existing dam body. The considered features in transient thermal analysis are; convective heat transfer, solar radiation and real boundary conditions applied on the body surface. Solar radiation shares of exposure surfaces are specified considering beam and diffuse radiation, latitude, azimuth of surface, declination of sun, slope of surface and reflectivity of ground and water [7].

Because of small thickness of the dam body adjacent to ground in comparison with other interfaces, foundation rock effect on temperature distribution was not considered 
in the study. In addition, dependency of thermal properties of concrete on temperature is eliminated. Figure 3 shows FEM of prepared model for thermal analysis. In this model, body thickness was divided to 5 layers and 8-node elements were used for modeling dam body as well as concrete saddle.

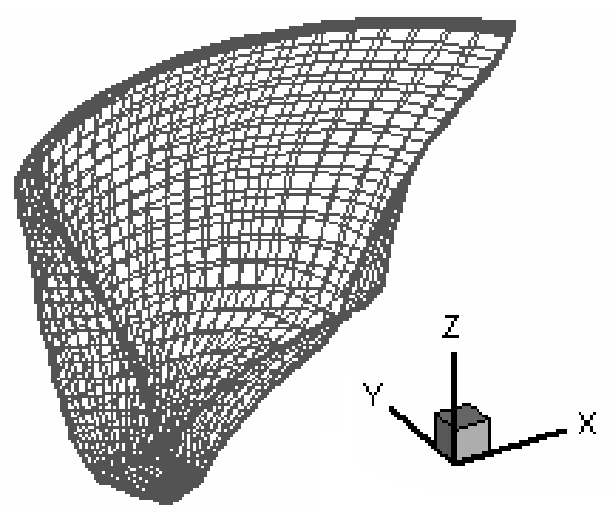

Fig. 3. FEM of dam and its Pulvino for thermal analysis.

\subsection{THERMAL BOUNDARY CONDITION}

\subsubsection{Ambient temperature}

Daily minimum and maximum temperature of the dam site has been measured using a thermometer located on the dam crest. Using these data a SIN graph was derived for ambient temperature changes of the dam site (Figure 4). Based on the dam site coordinate and sunshine data received from the nearest synoptic station (DEZFUL station), beam and diffused values of solar radiation were calculated and used in the model.

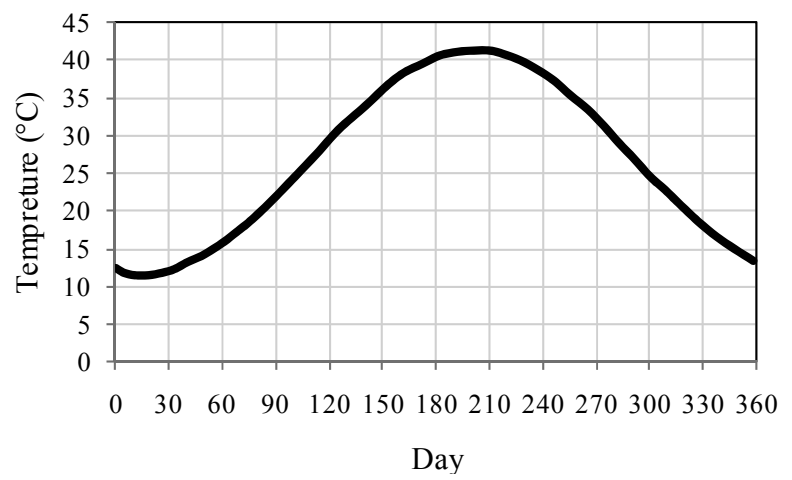

Fig. 4. Air temperature time-history extracted from daily average temperature. 


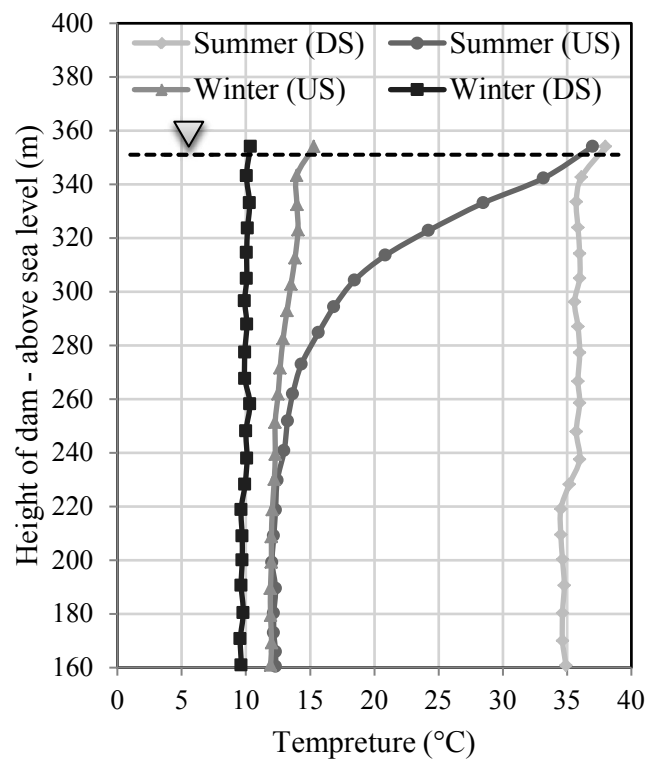

(a)

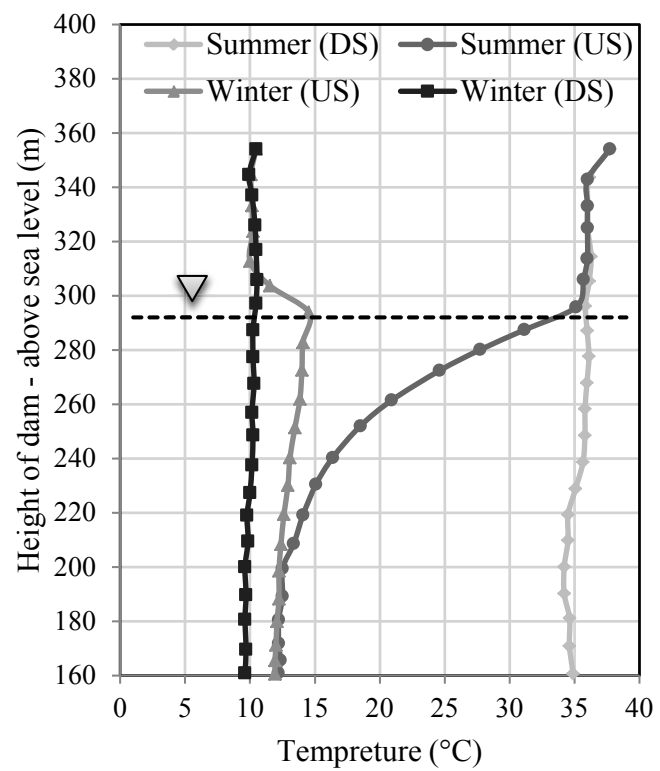

(b)

Fig. 5. Temperature distribution on dam upstream and downstream faces for (a) NWL, (b) MWL.

\subsubsection{Water temperature distribution}

Water temperature distribution depends on the depth of the reservoir at the considered time and the ambient temperature. In the current study, Bofang [8] method was utilized to obtain the distribution of temperature along the depth of the reservoir at specified times. Figure 5 exhibits summer and winter thermal distribution on dam-reservoir interface determined for NWL and MWL.

\subsection{Thermal Calibration procedure}

Temperature distribution through the existing dam body is obtained conducting a transient heat transfer analysis. Table 2 shows material properties used in the conducted thermal analyses.

DEZ dam have 20 thermometers installed in central block in elevations 179, 280, 316.5 and 325 (five thermometer in each elevation). The results from numerical model shows excellent agreement with the data obtained from monitoring instruments. Figure 6 shows some of comparisons made during thermal calibration procedure. 
Table 2

Material properties used in transient thermal analysis

\begin{tabular}{|c|c|}
\hline Thermal conductivity $\left(\mathrm{J} / \mathrm{m}^{2} / \mathrm{C} /\right.$ day $)$ & 226368 \\
\hline Density multiplied by Specific Heat $\left(\mathrm{J} / \mathrm{m}^{3} / \mathrm{C}\right)$ & 2188800 \\
\hline Concrete surface emissivity & 0.88 \\
\hline Convection Coefficient $\left(\mathrm{J} / \mathrm{m}^{2} /\right.$ day $\left./ \mathrm{C}\right)$ & 1336608 \\
\hline Surface absorption Coefficient & 0.65 \\
\hline
\end{tabular}

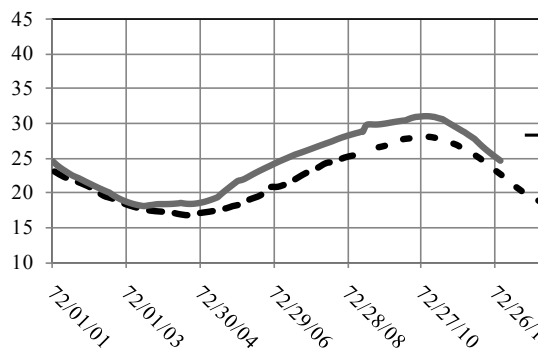

(a)

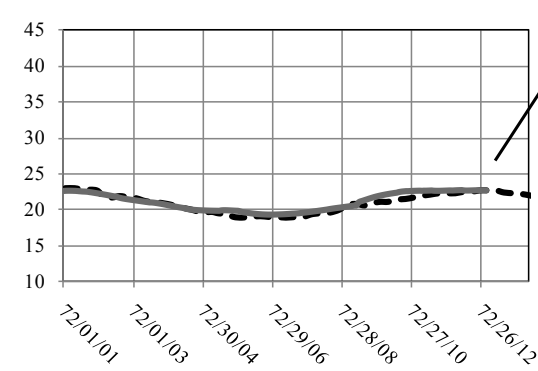

(c)

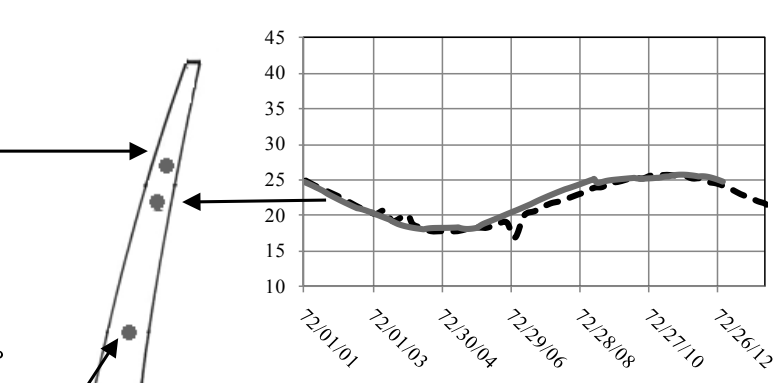

(b)

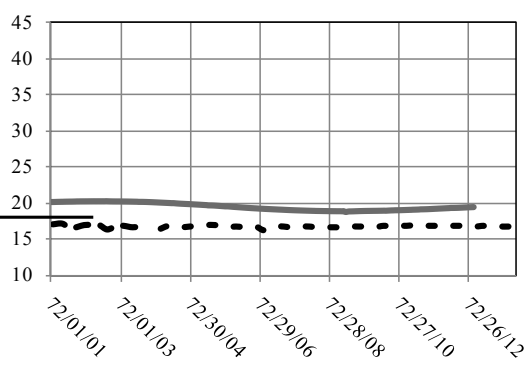

(d)

Fig. 6. Calibration results, central thermometers at (a) El. 328, (b) El. 316.5, (c) El. 280 and (d) El. 179 (Dash-line: measured data, Solid-line: model results).

\section{Static analysis}

In this stage, finite element model of the dam, foundation and reservoir were modeled based on as-built drawings and calibrated utilizing data recorded within several geodetic surviving performed during operating years of the system. At last, safety of existing dam was studied under static loads. 


\subsection{Preparing finite element model}

A 3D finite element model was prepared for considering static behavior of dam. In present model, main dam body and Pulvino were modeled using 792 eight-node solid elements in three layers. Foundation rock was modeled using 3770 eight-node solid elements and extended to at least twice the height of the dam body in all directions and up to surface of the rock in upward direction, reservoir water was modeled with eightnode fluid elements extended in upstream direction about 5 times of the height of the dam body. Based on topographic map of the dam site there is no opening in valley shape in distance up to $600 \mathrm{~m}$ of dam center. So it is acceptable assumption for simulation of reservoir with uniform section (like as dam upstream face). Figure 7 depicts FEM of dam body, foundation rock and reservoir medium.

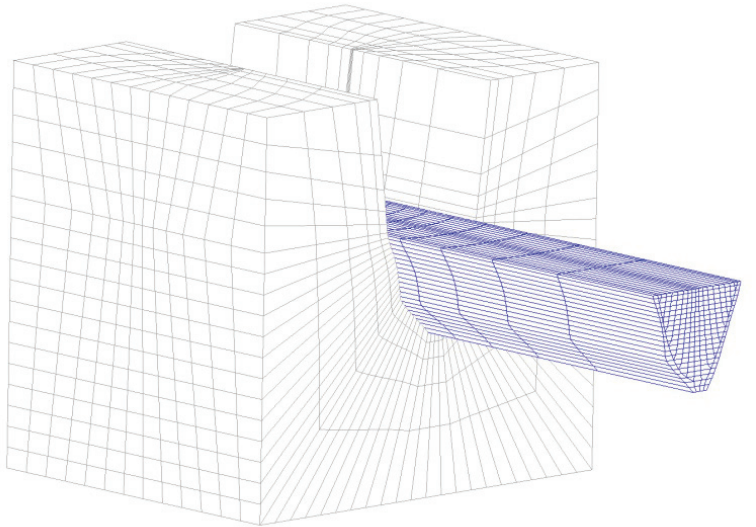

(a)

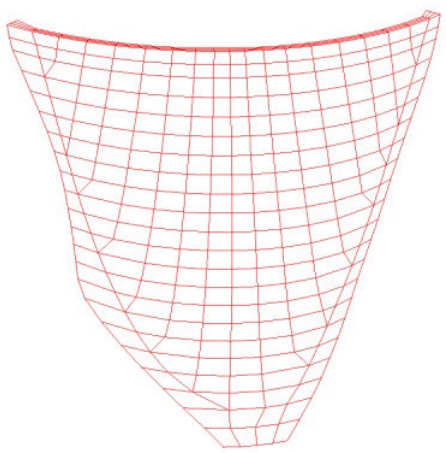

(b)

Fig. 7. Finite element model of (a) foundation rock and reservoir, (b) dam body and Pulvino.

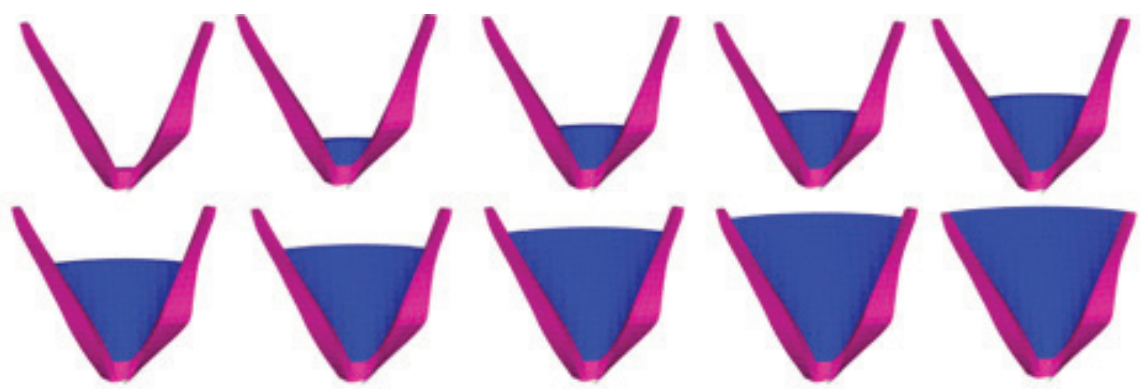

Fig. 8. Stage construction considered for static analyses. 
In order to considering effects of contraction joints as well as perimetral joint, they modeled based on as-built drawings using special 3D node-to-node contact elements. These elements are able to endure compression in normal direction to contact plane and also shear forces in contact plane. The perimetral joint was modeled in such a way that completely separate main dam body from Pulvino, but contraction joints are continuous up to near the perimetral joint and never don't cut them. Stage construction and sequence of vertical joints grouting are modeled based on available construction reports. Figure 8 shows ten stages taken into account in structural analyses.

\subsection{Static Calibration Procedure}

Considering reliability and accuracy of available 16 series of geodetic data obtained from micro geodesies measurement conducted on the dam site, series numbered $9^{\text {th }}$, $10^{\text {th }}, 11^{\text {th }}$ and $15^{\text {th }}$ are selected for calibrating the numerical model. The calibration procedure made during the current study can be briefly reviewed as following:

- Conducting transient thermal analysis for determining thermal distribution within the dam body at corresponding times and for corresponding reservoir water level and ambient temperature

- Conducting static analyses applying thermal, self weight, hydrostatic and silt load on the prepared finite element model of the system

- Conducting sensitive analyses on thermal expansion coefficient of mass concrete, elastic modulus of mass concrete, deformation modulus of saturated and unsaturated portions of foundation rock

Figure 9 shows point's location of geodetic measurement and Figures 10 to 12 shown the results obtained from the last set of sensitive analyses and as can be concluded, the responses of numerical model are in good agreement with those obtained using geodetic measurement.

As mentioned before contact elements used in present study act as a 3D spring in which support compression in normal direction to plane of interface and shears in tangential direction. Although normal and tangential stiffness have some effects on each other during movement of element, in present study we suppose that they act independent. Generally determination of exact values for normal $\left(\mathrm{K}_{\mathrm{n}}\right)$ and tangential $\left(\mathrm{K}_{\mathrm{s}}\right)$ stiffness is impossible because there are many unknown parameters in interaction and contact of two surfaces which are not considered in our simple model. So for determination of best values for $K_{n}$ and $K_{s}$ large range of values were supposed and sensitivity of results for these parameters were investigated. Generally zero value for stiffness means that there is no interaction between two surface of contact and considering very high values for stiffness coefficient means that two separate parts act as a unit part. Based on conducted analyses, considering $240 \mathrm{GPa} / \mathrm{m}$ for normal stiffness leads to opening about $1 \mathrm{~mm}$ in crest which is confirm the results obtained from joint-meter in this level. In addition tangential stiffness has been supposed $24 \mathrm{GPa} / \mathrm{m}$ (10\% normal stiffness) which is reasonable value in concrete arch dams. It is not worthy that $\mathrm{K}_{\mathrm{n}}$ and $\mathrm{K}_{\mathrm{s}}$ for peripheral 
joint are considered as $210 \mathrm{GPa} / \mathrm{m}$ and $16.8 \mathrm{GPa} / \mathrm{m}$ respectively. Based on the conducted static calibration procedure, mechanical properties of mass concrete and foundation rock are obtained given as in table 3 .

Plon Section 230.0

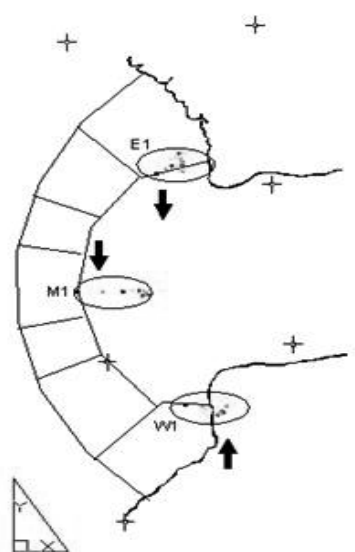

Plan Section 316.0

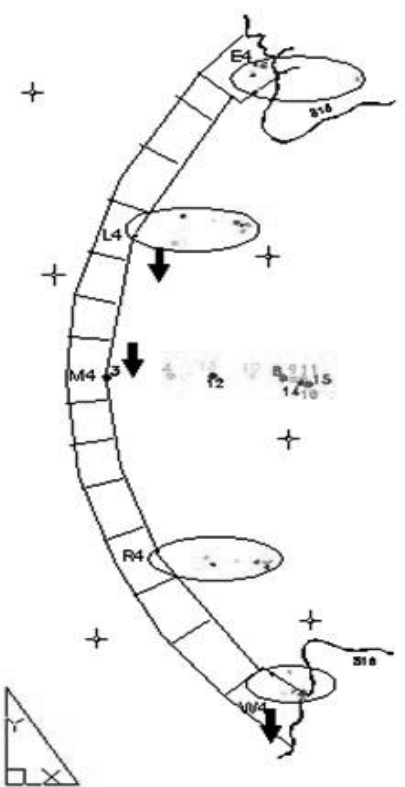

Plon Section 241.5

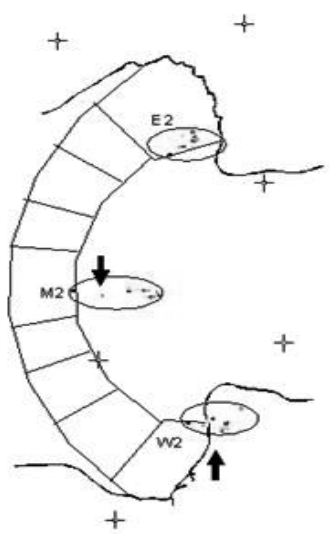

Plan Section 332.0

SCALE: I:1500

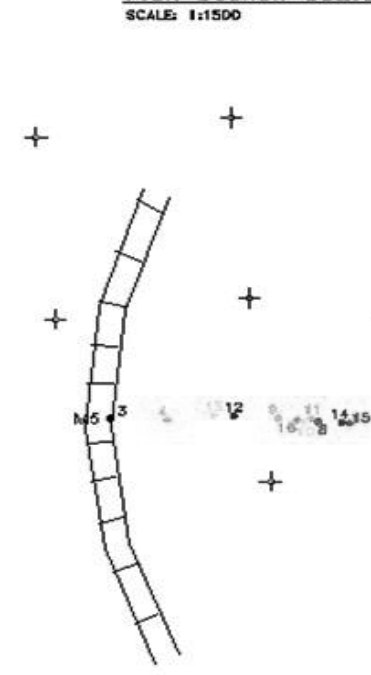

Plan Section 286.5

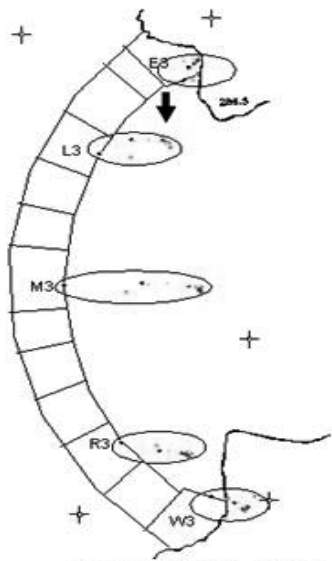

Plan Section 354.0 SCALE: 1:1500

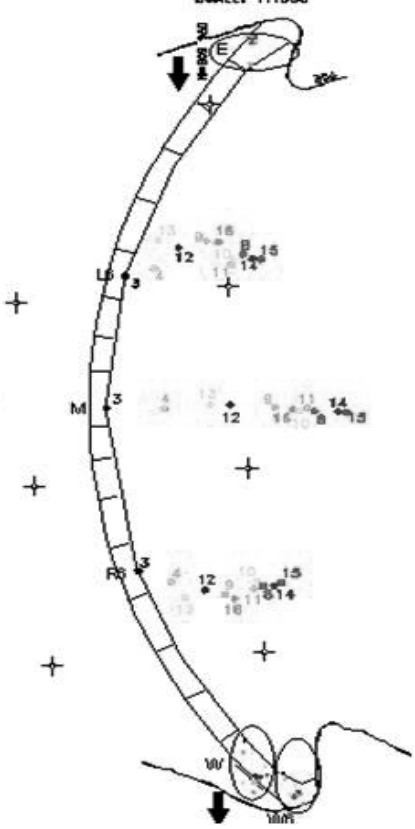

Fig. 9. Location of geodetic measures on the dam body at various elevations. 

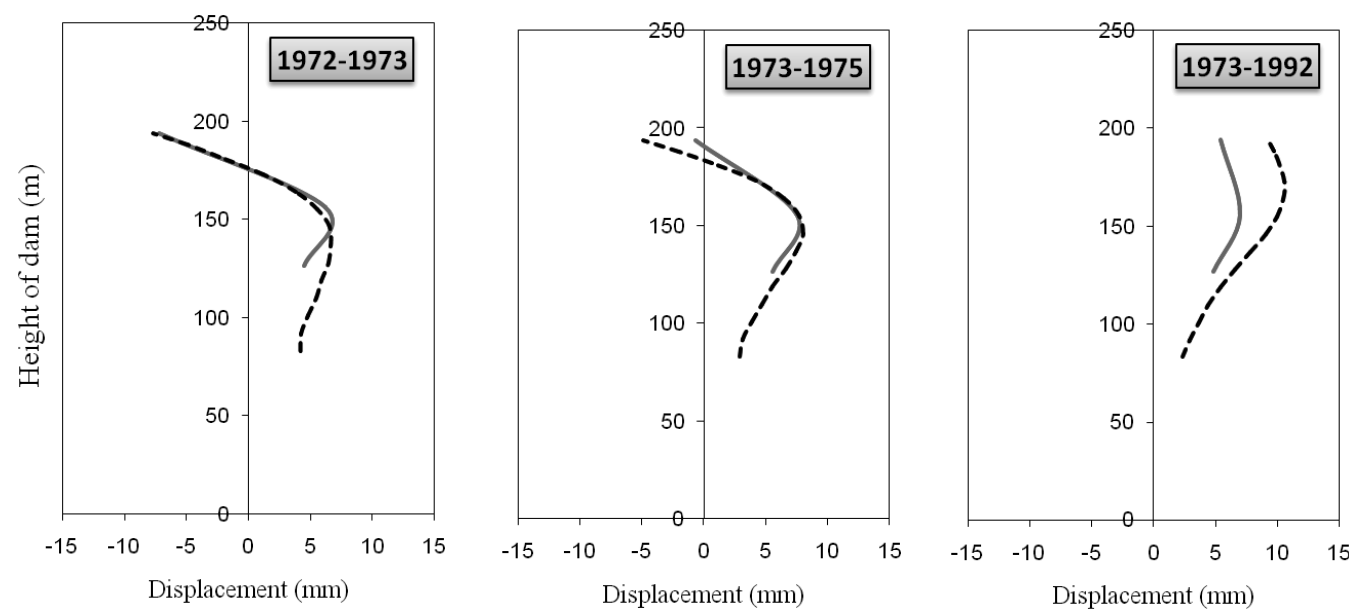

Fig. 10. Block R; comparison of data extracted from model and geodetic measurement (Dash-line: model results, Solid-line: measured data).
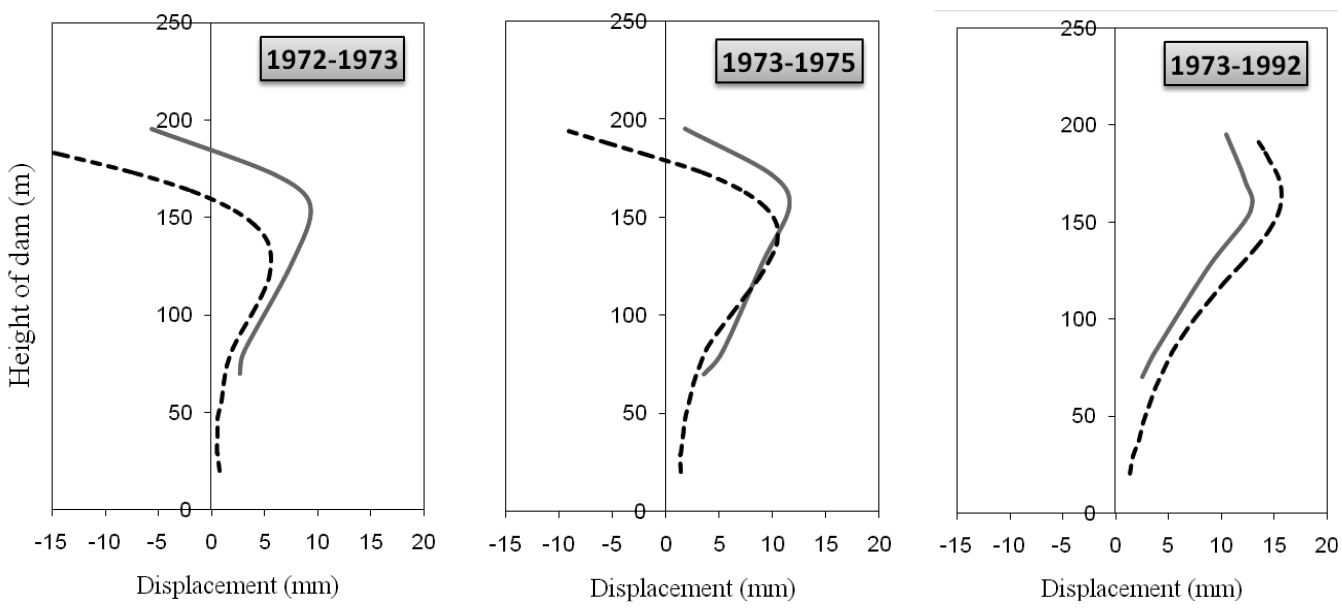

Fig. 11. Block M; comparison of data extracted from model and geodetic measurement

(Dash-line: model results, Solid-line: measured data). 

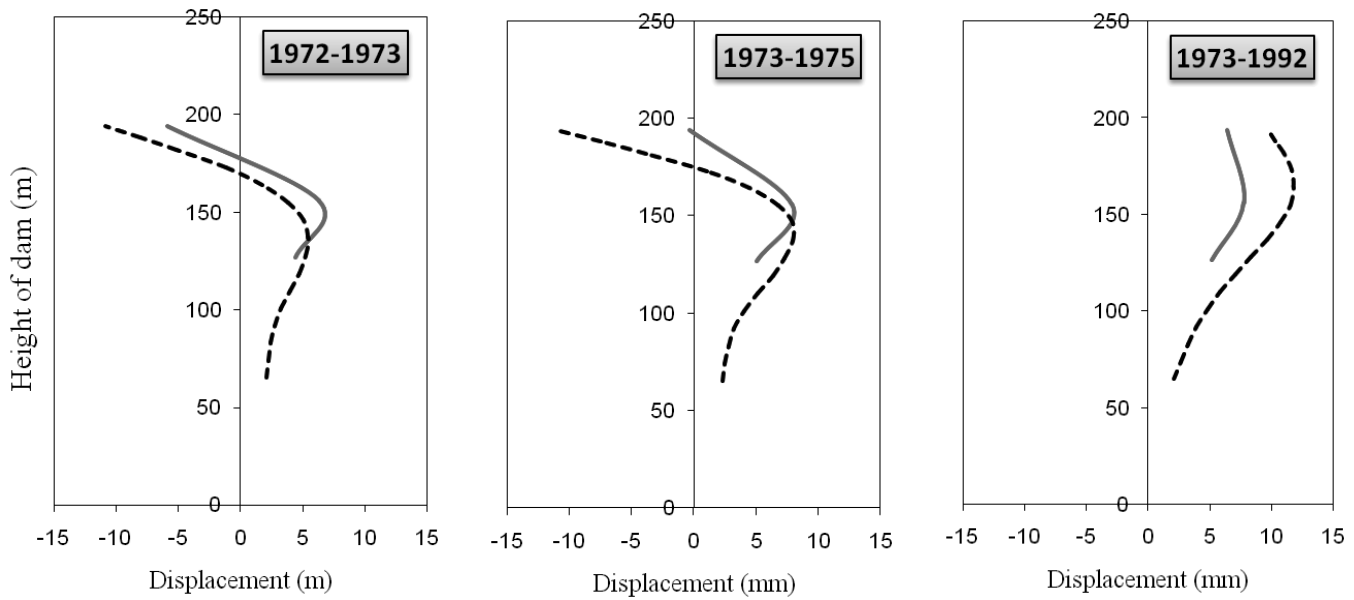

Fig. 12. Block L; comparison of data extracted from model and geodetic measurement (Dash-line: model results, Solid-line: measured data).

Table 3

Mechanical properties for mass concrete and foundation rock extracted from static calibration

\begin{tabular}{|c|c|c|}
\hline \multirow{4}{*}{ Mass concrete } & Density & $2400 \mathrm{~kg} / \mathrm{m}^{3}$ \\
\cline { 2 - 3 } & Modulus of elasticity & $40 \mathrm{GPa}$ \\
\cline { 2 - 3 } & Poison's ratio & 0.2 \\
\cline { 2 - 3 } & Thermal expansion coefficient & $6 * 10 \mathrm{E}-6 /{ }^{\circ} \mathrm{C}$ \\
\cline { 2 - 3 } Foundation rock & Grouting temperature & $23^{\circ} \mathrm{C}$ \\
\cline { 2 - 3 } & Deformation modulus (Saturated region $/$ Dry region) & $13 \mathrm{GPa}, 15 \mathrm{GPa}$ \\
\cline { 2 - 3 } & Unit weight (Saturated region/ Dry region) & $25 \mathrm{kN} / \mathrm{m}^{3}, 24 \mathrm{kN} / \mathrm{m}^{3}$ \\
\cline { 2 - 3 } & Poison's ratio (Saturated and dry region) & 0.25 \\
\hline
\end{tabular}

\subsubsection{Discussion on results of calibration procedure}

For discussion on modules of elasticity of mass concrete, it is worthy to refer to EM 1110-2-2201 published by USACE [9], in which the following paragraph can be found: "The instantaneous modulus of elasticity is the static modulus of elasticity. The modulus of elasticity in tension is usually assumed to be equal to that in compression. Therefore, no separate modulus testing in tension is required. Typical values for instantaneous (static) modulus of elasticity will range from $24.5 \mathrm{GPa}$ to $38.5 \mathrm{GPa}$ at 28 days and from $30.1 \mathrm{GPa}$ to $47.6 \mathrm{GPa}$ at 1 year." Based on data presented in table 3 , the elastic modulus for mass concrete in existing DEZ dam is obtained to be $40 \mathrm{GPa}$ which is expectable because of age of dam. 


\subsection{Static safety evaluation}

For considering static safety of existing dam, load combinations specified by FERC [5] are considered as governing combinations. Table 4 represents these load combinations based on operating data of existing dam. Moreover, based on available data and international references, the uni-axial compressive strength and tensile strength of mass concrete is taken as $35 \mathrm{MPa}$ and $3.4 \mathrm{MPa}$ respectively. In addition this table presents factor of safeties utilized for static safety evaluation of existing dam [5]. Based on this information, the allowable tensile and compressive stresses for mass concrete can be determined as given in two last columns of table 4.

Table 4

Load combinations, factor of safeties and allowable stresses in static condition

\begin{tabular}{|c|c|c|c|c|c|c|}
\hline \multirow{2}{*}{\multicolumn{2}{|c|}{$\begin{array}{c}\text { Load } \\
\text { combination }\end{array}$}} & \multirow{3}{*}{$\begin{array}{c}\text { Description } \\
\mathrm{S}^{*}+\mathrm{T}^{* *}\left(\underset{\mathrm{S} \text { silt }}{\text { summer }}+\mathrm{NWL} \mathrm{L}^{\dagger}+\right.\end{array}$} & \multicolumn{2}{|c|}{ Factor of safety } & \multicolumn{2}{|c|}{ Allowable stresses } \\
\hline & & & Tensile & Compressive & Tensile & Compressive \\
\hline \multirow{2}{*}{$\begin{array}{l}\text { Static } \\
\text { Usual }\end{array}$} & SU1 & & \multirow[t]{2}{*}{2.0} & \multirow[t]{2}{*}{1.0} & \multirow[t]{2}{*}{$17.5 \mathrm{MPa}$} & \multirow[t]{2}{*}{$3.4 \mathrm{MPa}$} \\
\hline & SU2 & $\mathrm{S}+\mathrm{T}($ winter $)+\mathrm{NWL}+$ Silt & & & & \\
\hline \multirow{4}{*}{$\begin{array}{c}\text { Static } \\
\text { Unusual }\end{array}$} & SUN1 & $\begin{array}{c}\mathrm{S}+\mathrm{T}(\text { summer })+\mathrm{FWL}^{\dagger \dagger}+ \\
\text { Silt }\end{array}$ & \multirow{4}{*}{1.5} & \multirow{4}{*}{1.0} & \multirow{4}{*}{$23.3 \mathrm{MPa}$} & \multirow{4}{*}{$3.4 \mathrm{MPa}$} \\
\hline & SUN2 & $\mathrm{S}+\mathrm{T}($ winter $)+\mathrm{FWL}+$ Silt & & & & \\
\hline & SUN3 & $\begin{array}{c}\mathrm{S}+\mathrm{T} \text { (summer) }+\mathrm{MWL}^{\dagger \dagger \dagger}+ \\
\text { Silt }\end{array}$ & & & & \\
\hline & SUN4 & $\mathrm{S}+\mathrm{T}($ winter $)+\mathrm{MWL}+$ Silt & & & & \\
\hline
\end{tabular}

* Dead load; ${ }^{* *}$ Temperature.

${ }^{\dagger}$ Normal Water Level; ${ }^{\dagger \dagger}$ Flood Water Level; ${ }^{\dagger \dagger}$ Maximum Water Level.

Figures 13 and 14 show envelope of maximum first principal stress (S1) on upstream and downstream faces of existing dam body extracted from static load combinations pointed in table 4. Also the same plots are depicted in figures 15 and 16 for minimum third principal stress (S3). Considering the allowable stresses for tensile and compressive stresses, it can be seen that in all cases the values obtained for stress from analyses the dam in static condition are in acceptable range and dam is evaluated to have safe behavior in this condition. The results of this section are summarized in tables 5 and 6 as well. For evaluating stress state in each nodal point within the existing dam, both uniaxial and biaxial failure curve of mass concrete are utilized. For providing biaxial failure curve, the modified relationships represented by Kupfer et al. [10] have been utilized in the current study. As can be seen in Figure 17 in all cases the stresses within the dam body satisfy the uniaxial and biaxial failure criteria. 


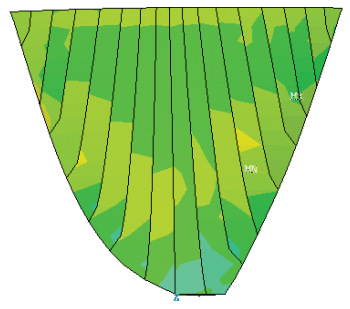

SU1

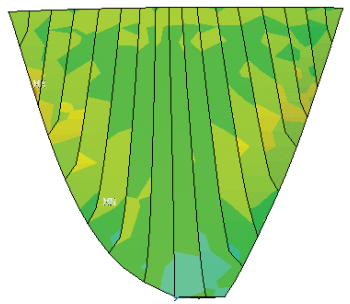

SUN2

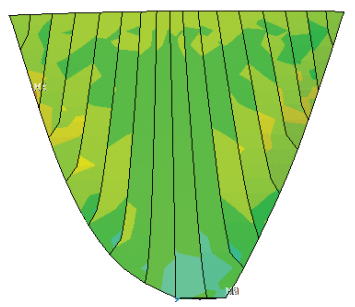

SU2

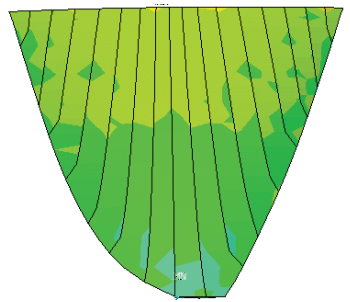

SUN3

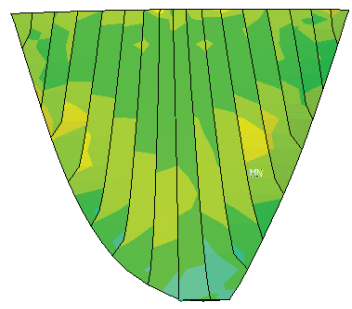

SUN1

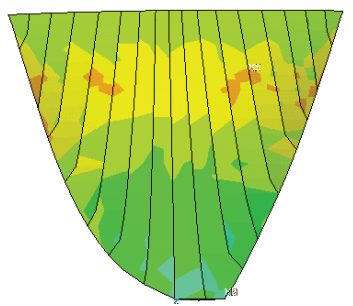

SUN4

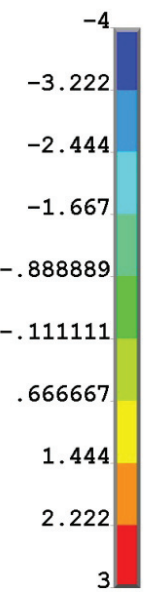

Fig. 13. Envelope of maximum first principal stress in static condition, upstream face, MPa.
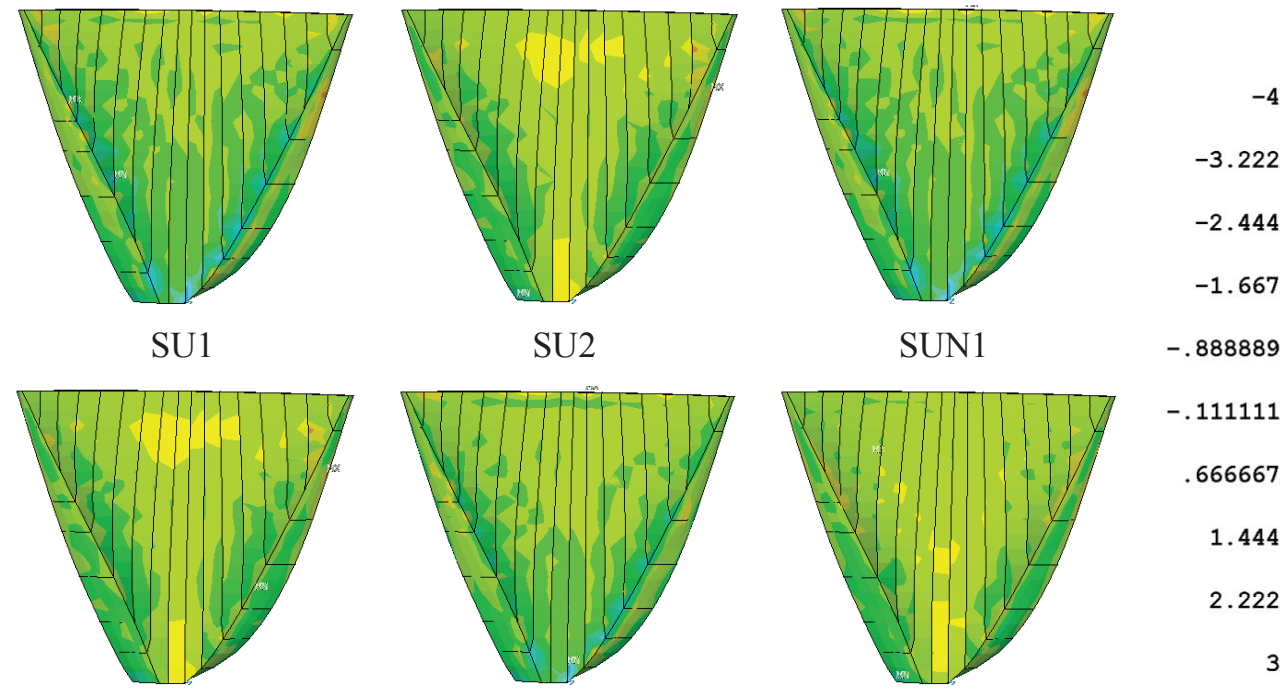

SUN2
SUN3

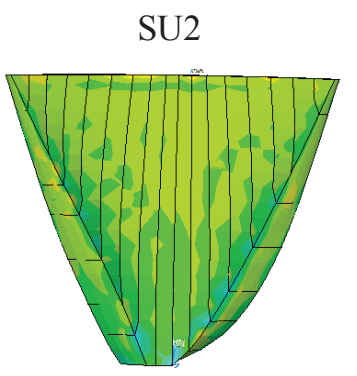

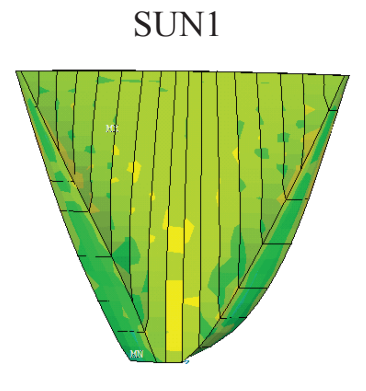

$-.888889$

$-.111111$

.666667

1.444

2.222

SUN4

Fig. 14. Envelope of maximum first principal stress in static condition, downstream face, MPa. 


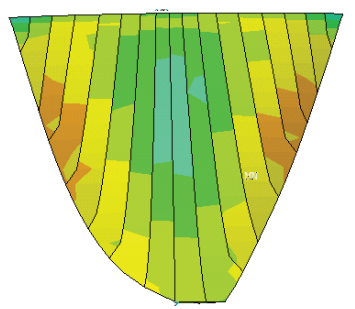

SU1

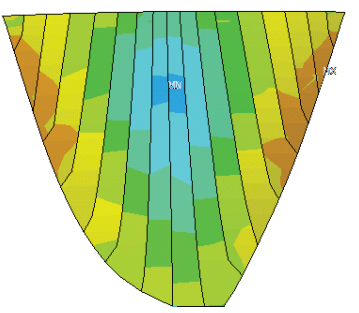

SUN2

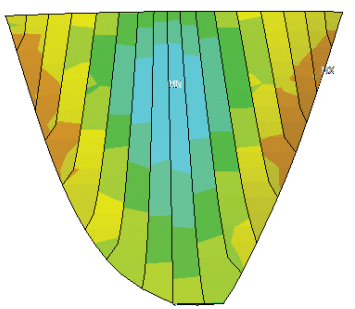

SU2

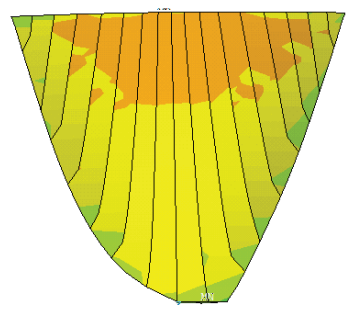

SUN3
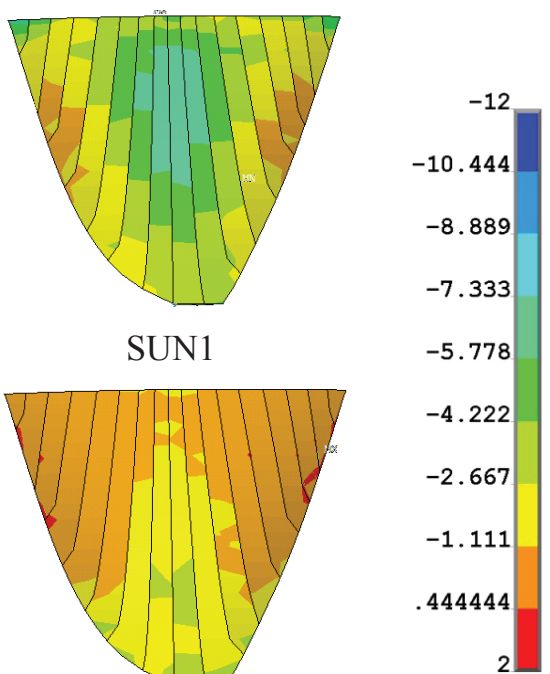

SUN4

Fig. 15. Envelope of minimum third principal stress in static condition, upstream face, MPa.

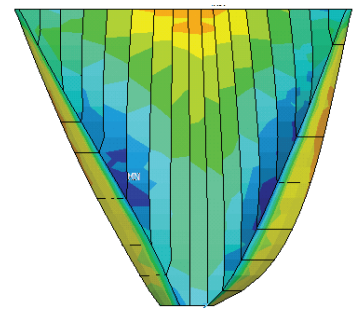

SU1

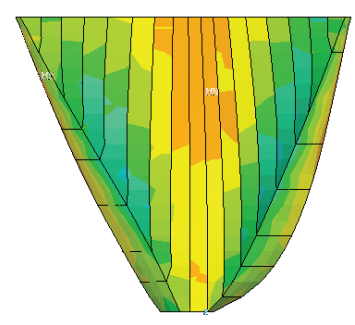

SUN2

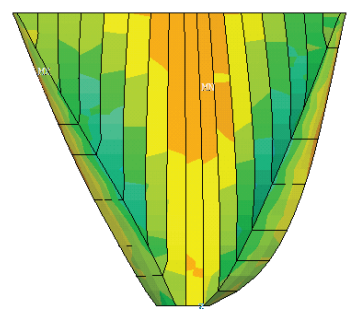

SU2

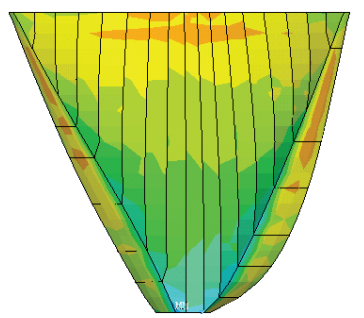

SUN3
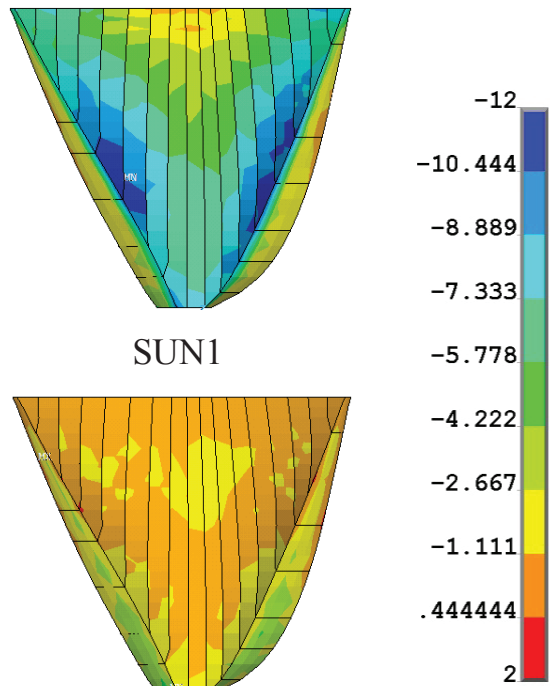

SUN4

Fig. 16. Envelope of minimum third principal stress in static condition, downstream face, MPa. 


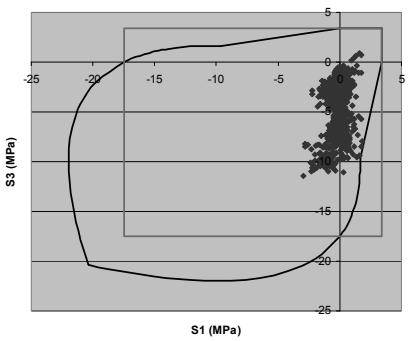

SU1

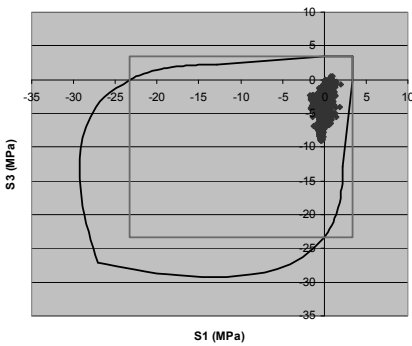

SUN2

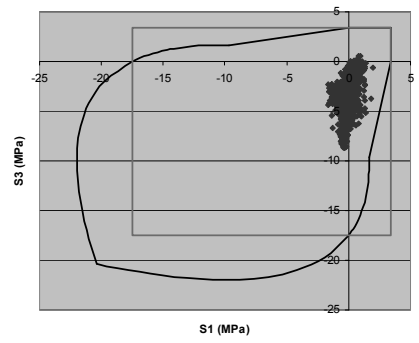

SU2

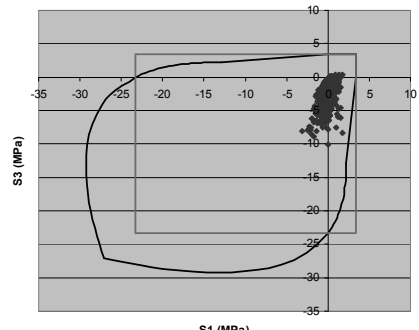

SUN3

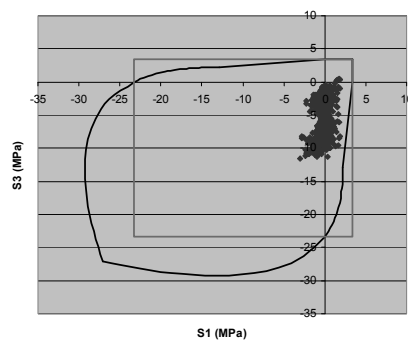

SUN1

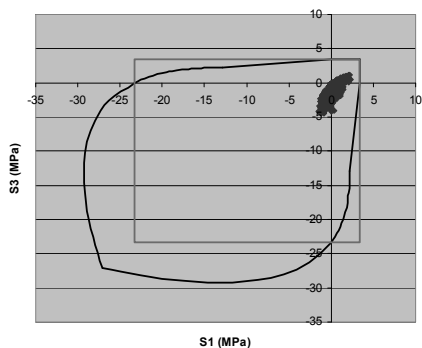

SUN4

Fig. 17. Comparison of dam body principal stresses with uniaxial and biaxial failure curves in static condition ( + sign is tensile stress and - sign is compressive stress).

Table 5

Extreme tensile stresses in dam body

\begin{tabular}{|c|c|c|c|}
\hline \multicolumn{2}{|c|}{ Load combination } & Stress value & Location \\
\hline \multirow{3}{*}{ Static Usual } & SU1 & $1.850 \mathrm{MPa}$ & Downstream face, interface of dam-abutment, level $297 \mathrm{~m}$ \\
\cline { 2 - 5 } & SU2 & $1.950 \mathrm{MPa}$ & Upstream face, interface of dam-abutment, level 306m \\
\hline \multirow{5}{*}{ Static Unusual } & SUN1 & $1.911 \mathrm{MPa}$ & Central block, crest level \\
\cline { 2 - 4 } & SUN2 & $2.000 \mathrm{MPa}$ & Upstream face, interface of dam-abutment, level $306 \mathrm{~m}$ \\
\cline { 2 - 4 } & SUN3 & $1.810 \mathrm{MPa}$ & Central block, crest level \\
\cline { 2 - 4 } & SUN4 & $2.290 \mathrm{MPa}$ & Upstream face, inner block, level $315 \mathrm{~m}$ \\
\hline
\end{tabular}


Table 6

Extreme compressive stresses in dam body

\begin{tabular}{|c|c|c|c|}
\hline \multicolumn{2}{|c|}{ Load combination } & Stress value & Location \\
\hline \multirow{3}{*}{ Static Usual } & SU1 & $11.420 \mathrm{MPa}$ & Downstream face, interface of dam-abutment, level $252 \mathrm{~m}$ \\
\cline { 2 - 4 } & SU2 & $8.690 \mathrm{MPa}$ & Upstream face, central block, level $306 \mathrm{~m}$ \\
\hline \multirow{4}{*}{ Static Unusual } & SUN1 & $11.630 \mathrm{MPa}$ & Downstream face, interface of dam-abutment, level $252 \mathrm{~m}$ \\
\cline { 2 - 4 } & SUN2 & $9.070 \mathrm{MPa}$ & Upstream face, central block, level $306 \mathrm{~m}$ \\
\cline { 2 - 4 } & SUN3 & $10.050 \mathrm{MPa}$ & Downstream face, dam-Pulvino interface \\
\cline { 2 - 4 } & SUN4 & $4.520 \mathrm{MPa}$ & Downstream face, dam-Pulvino interface \\
\hline
\end{tabular}

\section{DyNAMic ANALYSIS}

\subsection{Appropriate acCelerograms for analyses}

Based on ICOLD 1989 [11] three excitation hazard levels should be considered for seismic design and evaluation of dam-reservoir-foundation system that are Design Base Level (DBL), Maximum Design Level (MDL) and Maximum Credible Level (MCL). Generally, seismic performance evaluation of arch dams is done under Maximum Credible Earthquakes (MCEs) considering linear elastic (LE) material for mass concrete and then sufficiency of LE analyses or requirement to nonlinear analyses is investigate. But in the present paper, our investigations are directly focused on seismic analysis of dam-reservoir-foundation system considering material and joint nonlinearities for the system. Based on seismic hazard analysis of dam site, design spectrum of horizontal and vertical components for MCL are extracted considering $\xi=5 \%$ as shown in figure 18. Also figure 19 shows three components of MCEs which are selected based on source characteristics, source-to-site transmission path properties, and site conditions.

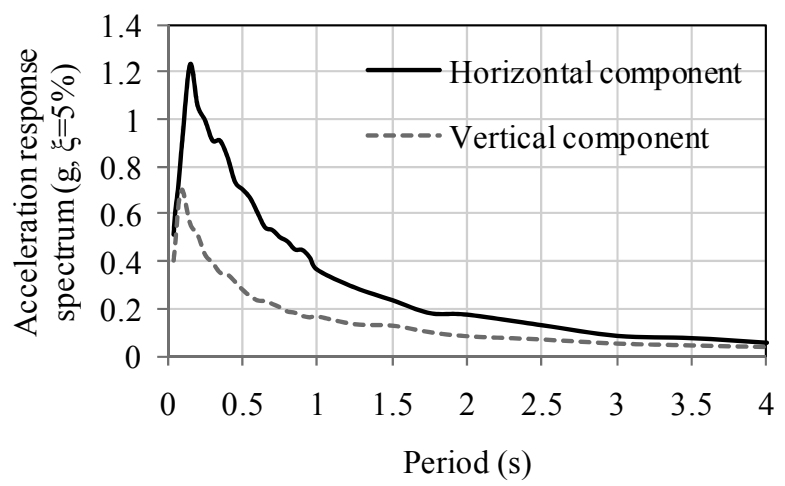

Fig. 18. Response spectrum of MCL. 


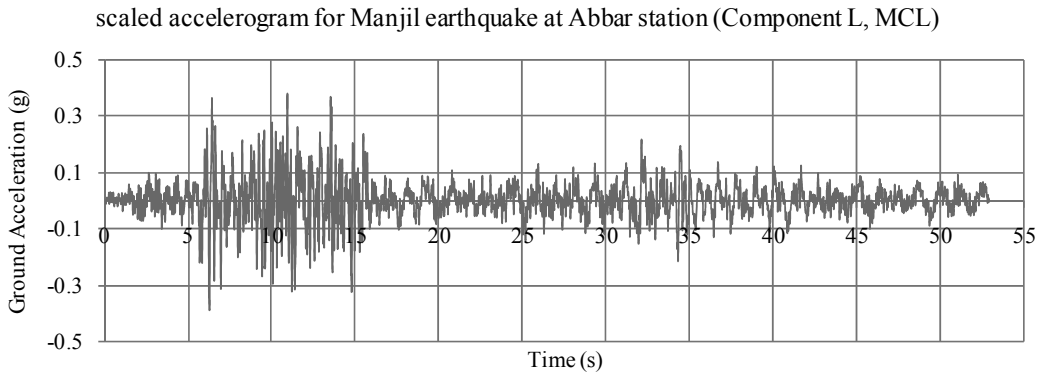

scaled accelerogram for Manjil earthquake at Abbar station (Component T, MCL)

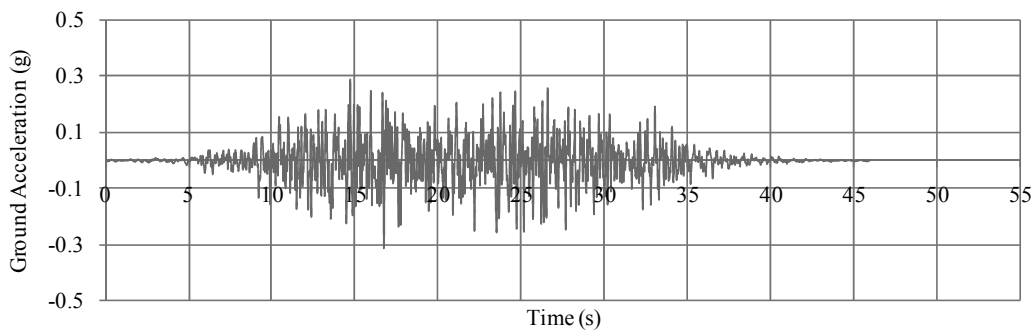

scaled accelerogram for Manjil earthquake at Abbar station (Component V, MCL)

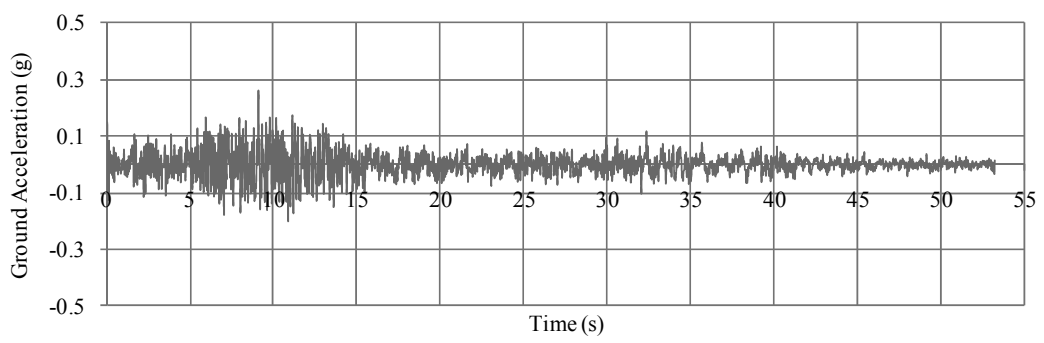

Fig. 19. Horizontal and vertical components of Manjil ground motion in MCL.

\subsection{Main assumptions For DyNAMIC ANALYSIS}

The main assumptions in conducted dynamic analyses are as follows:

- Foundation rock is assumed mass less.

- Structural damping is applied to the equilibrium equations using RAIGHLEY stiffness and mass proportional damping. Damping for MCE excitation level is assumed $7.5 \%$ of critical damping. Frequencies $2 \mathrm{~Hz}$ and $6 \mathrm{~Hz}$ were selected in order to calculation of stiffness and mass proportional damping ratios.

- Reservoir is compressible.

- Wave reflection coefficient applied on bottom and sides of the reservoir medium is taken to be 0.8 , conservatively. Hydrodynamic pressure on free surface of the reservoir is neglected and far-end boundary of finite element model of reservoir medium absorbs outgoing pressure waves completely. 


\subsection{Mechanical and StRENGTH PROPERTIES}

Due to rate dependence of mechanical and strength properties of mass concrete, based on FERC and USACE engineering manuals, table 7 presents the dynamic properties used in seismic analyses of the system.

Table 7

Mechanical and strength properties in static and dynamic conditions

\begin{tabular}{|c|c|c|c|c|c|}
\hline & $\mathbf{E}_{\mathbf{C}}$ & $\mathbf{E}_{\mathbf{F}}$ & $\mathbf{v}$ & $\mathbf{F}_{\mathbf{C}}$ & $\mathbf{F}_{\mathbf{t}}$ \\
\hline STATIC & $40 \mathrm{GPa}$ & $13-15 \mathrm{GPa}$ & 0.2 & $35 \mathrm{MPa}$ & $3.4 \mathrm{MPa}$ \\
\hline DYNAMIC & $46 \mathrm{GPa}$ & $13-15 \mathrm{GPa}$ & 0.14 & $36.5 \mathrm{MPa}$ & $5.1 \mathrm{MPa}^{*}$ \\
\hline
\end{tabular}

* For taking into account lift joint effects it reduce to $4.0 \mathrm{MPa}$

\subsection{Preparing Finite element model}

For evaluating behavior of existing dam in MCL, a finite element model is used where joint and material nonlinearities were used in model. In material nonlinearity model Gaussian points within mass concrete elements can be cracked due to tensile stresses and can be crushed due to compressive stresses based on tensile and compressive strength of mass concrete.

\subsubsection{Material nonlinearity model}

A smeared crack model was used in order to modeling mass concrete cracking and crushing effects under seismic loads. In present model initiation of the fracture process, determined by a suitable constitutive model, the pre-crack material stress-strain relation is replaced by an orthotropic relation with material reference axis system aligned with the fracture direction. Thus, only the constitutive relation is updated with propagation of cracks and the finite element mesh is kept unchanged. In this model, it is assumed that concrete material is initially (before cracking) isotropic and linear until it reaches ultimate strength and the elasticity modulus of concrete is considered as the average, $E$, instead of the linear actual, $E_{0}$. Stress increases linearly along with an increase in strain. In this step, each reloading of elements leads to elastic returning of strain. The stressstrain matrix is defined by the Eq. 2 where $v$ is Poisson's ratio. 
(2)

$$
\left[D_{\text {linear }}\right]=\frac{E}{(1+v)(1-2 v)}\left[\begin{array}{cccccc}
(1-v) & v & v & 0 & 0 & 0 \\
v & (1-v) & v & 0 & 0 & 0 \\
v & v & (1-v) & 0 & 0 & 0 \\
0 & 0 & 0 & \frac{1-2 v}{2} & 0 & 0 \\
0 & 0 & 0 & 0 & \frac{1-2 v}{2} & 0 \\
0 & 0 & 0 & 0 & 0 & \frac{1-2 v}{2}
\end{array}\right]
$$

Cracking occurs when principal tensile stress in any direction lies outside the failure surface. In this model cracking is permitted in three orthogonal directions at each Gaussian point. When cracking occurs at a Gaussian point, the stress-strain relation is modified by defining a weak plane normal to the crack direction. Also crushing occurs when all principal stresses are compressive and lie outside the failure surface; in this condition, the elastic modulus is set to zero in all directions. The presence of crack at a Gaussian point and in special direction, represent through modification of stiffens matrix by exerting shear transfer coefficient in cracked plane. Based on the fact that concrete has been cracked in one, two or three orthogonal directions, the stiffness matrix can be represented in following forms:

I) Concrete has been cracked in one direction and the crack is open:

$$
\left[D_{\text {cracked }}^{\text {open }}\right]=\frac{E}{1+v}\left[\begin{array}{cccccc}
\frac{E^{S}(1+v)}{E} & 0 & 0 & 0 & 0 & 0 \\
0 & \frac{1}{1-v} & \frac{v}{1-v} & 0 & 0 & 0 \\
0 & \frac{v}{1-v} & \frac{1}{1-v} & 0 & 0 & 0 \\
0 & 0 & 0 & \frac{\beta_{\text {open }}}{2} & 0 & 0 \\
0 & 0 & 0 & 0 & \frac{1}{2} & 0 \\
0 & 0 & 0 & 0 & 0 & \frac{\beta_{\text {open }}}{2}
\end{array}\right]
$$


where $E^{S}$ represents secant modulus and $\beta_{\text {open }}$ is open shear transfer coefficient and defined as the factor that represents shear strength reduction across the cracked face.

II) Concrete has been cracked in one direction and the crack is closed:

(4) $\left[D_{\text {craced }}^{\text {closed }}\right]=\frac{E}{(1+v)(1-2 v)}\left[\begin{array}{cccccc}(1-v) & v & v & 0 & 0 & 0 \\ v & (1-v) & v & 0 & 0 & 0 \\ v & v & (1-v) & 0 & 0 & 0 \\ 0 & 0 & 0 & \frac{\beta_{\text {close }}(1-2 v)}{2} & 0 & 0 \\ 0 & 0 & 0 & 0 & \frac{1-2 v}{2} & 0 \\ 0 & 0 & 0 & 0 & 0 & \frac{\beta_{\text {close }}(1-2 v)}{2}\end{array}\right]$

where $\beta_{\text {closed }}$ is closed shear transfer coefficient. The shear transfer coefficient, $\beta$, represents conditions of the crack face. The value of $\beta$ ranges from 0.0 to 1.0, with 0.0 representing smooth crack (complete loss of shear transfer) and 1.0 representing a rough crack (no loss of shear transfer).

III) Concrete has been cracked in two directions and the cracks are open:

(5)

$$
\left[D_{\text {cracked }}^{\text {open }}\right]=E\left[\begin{array}{cccccc}
\frac{E^{S}}{E} & 0 & 0 & 0 & 0 & 0 \\
0 & \frac{E^{S}}{E} & 0 & 0 & 0 & 0 \\
0 & 0 & 1 & 0 & 0 & 0 \\
0 & 0 & 0 & \frac{\beta_{\text {open }}}{2(1+v)} & 0 & 0 \\
0 & 0 & 0 & 0 & \frac{\beta_{\text {open }}}{1(1+v)} & 0 \\
0 & 0 & 0 & 0 & 0 & \frac{\beta_{\text {open }}}{2(1+v)}
\end{array}\right]
$$


IV) Concrete has been cracked in two directions and both cracks are closed:

$(6)\left[D_{\text {cracked }}^{\text {clsaed }}\right]=\frac{E}{(1+v)(1-2 v)}\left[\begin{array}{cccccc}(1-v) & v & v & 0 & 0 & 0 \\ v & (1-v) & v & 0 & 0 & 0 \\ v & v & (1-v) & 0 & 0 & 0 \\ 0 & 0 & 0 & \frac{\beta_{\text {close }}(1-2 v)}{2} & 0 & 0 \\ 0 & 0 & 0 & 0 & \frac{(1-2 v)}{2} & 0 \\ 0 & 0 & 0 & 0 & 0 & \frac{\beta_{\text {close }}(1-2 v)}{2}\end{array}\right]$

V) Concrete has been cracked in three directions and the cracks are open:

(7)

$$
\left[D_{\text {cracked }}^{\text {open }}\right]=E\left[\begin{array}{cccccc}
\frac{E^{S}}{E} & 0 & 0 & 0 & 0 & 0 \\
0 & \frac{E^{S}}{E} & 0 & 0 & 0 & 0 \\
0 & 0 & 1 & 0 & 0 & 0 \\
0 & 0 & 0 & \frac{\beta_{\text {open }}}{2(1+v)} & 0 & 0 \\
0 & 0 & 0 & 0 & \frac{\beta_{\text {open }}}{2(1+v)} & 0 \\
0 & 0 & 0 & 0 & 0 & \frac{\beta_{\text {open }}}{2(1+v)}
\end{array}\right]
$$

VI) Concrete has been cracked in three directions and all cracks are closed. In this situation Eq. 6 can be written again. It should be noted that all above stress-strain relations are written in local coordinate system that is parallel to principal stress directions. 


\subsubsection{Joint nonlinearity model}

In the present study, all contraction and peripheral joints were modeled using nodeto-node 3D contact elements. These contact elements support only the compression in normal on the joint face and also shears in the tangential direction. Figure 20 shows the flowchart used for calculating force in contact elements. In this figure, $\vec{V}$ is a vector representing contact state in which $\mathrm{V}_{\mathrm{n}}$ indicates the state in the normal direction to the plane of the joint, and; $\mathrm{V}_{\mathrm{r}}$ and $\mathrm{V}_{\mathrm{s}}$ indicate the state of the considered contact element in tangential directions. Moreover, this figure shows force-deflection relations for both normal and tangential status. In this flowchart $F_{n}, F_{r}$ and $F_{s}$ are local components of the force vector, $F_{g}$ is sliding force in the joint, $F_{t}$ is shear force resultant, $K_{n}$ and $K_{t}$ are normal and tangential stiffness of the joint and ' $\alpha$ ' is angle between the two components of the in-plane shear. These contact elements cannot endure any tensile force or stress, but when it is in compression, it can suffer compression forces according to its normal stiffness coefficient and shear forces according to its tangential stiffness coefficient. When shear force resultant in the joint exceeds from joint sliding resisting force, the two nodes of the element begin sliding with respect to each other. Joint sliding force is calculated using coulomb elastic friction law, in which $\mathrm{c}$ is cohesion factor and $\mu$ is friction coefficient.

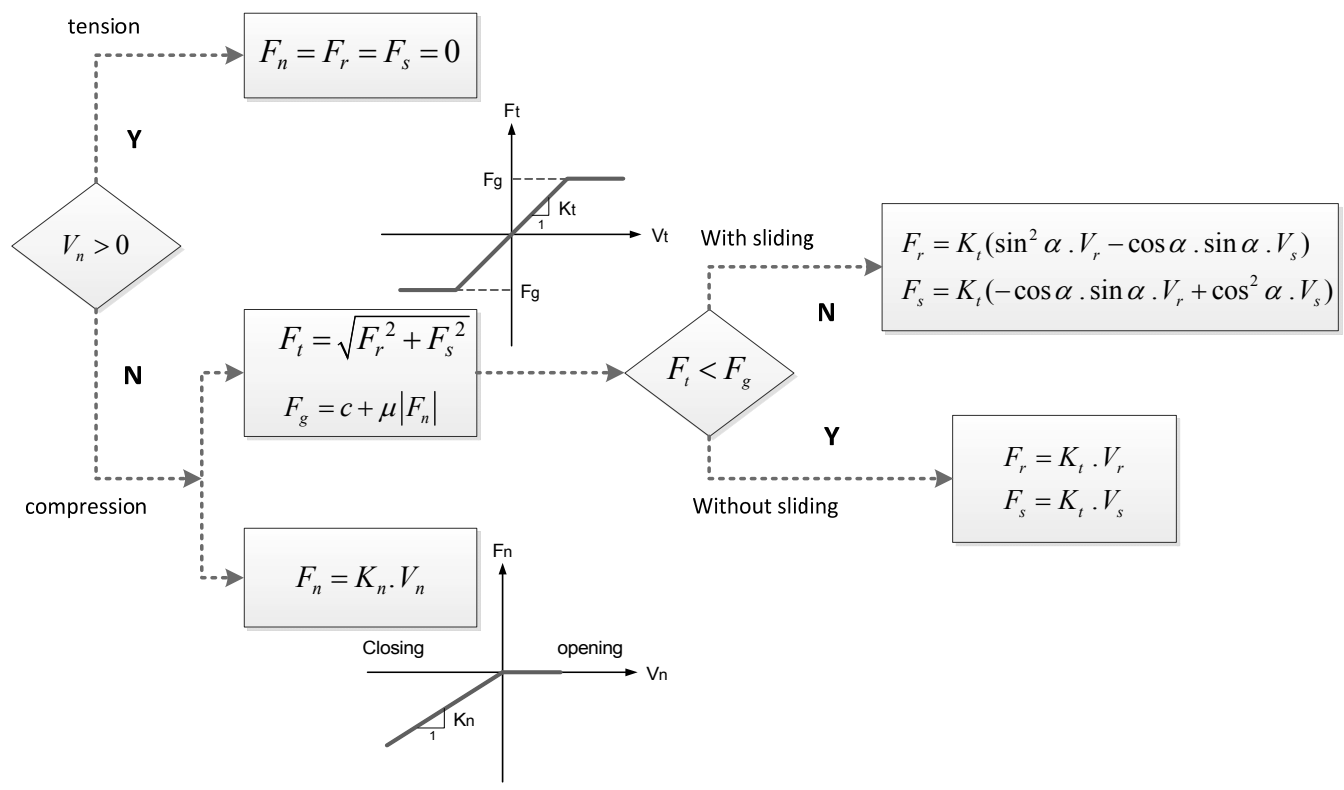

Fig. 20. Flowchart for calculating force in joints and also force-deflection relations for joint. 


\subsection{LOAD COMBINATIONS AND ANALYSES}

Considering conducted dynamic analyses in MCL, MANJIL earthquake record scaled based on site response spectrum is governing earthquake and in the current paper, corresponding load combinations as presented in table 8 are considered. It is noteworthy that based on analyses conducted by authors, Manjil earthquake is most critical one among all selected ground motions for analysis of DEZ dam. In addition thermal load due to winter temperature has worst effect than summer temperature.

Table 8

Load combinations in MCE level

\begin{tabular}{|c|c|}
\hline Load combination & Description \\
\hline DE1 & $\mathrm{S}+\mathrm{T}($ winter $)+\mathrm{NWL}+\mathrm{Silt}+\mathrm{E}^{\S}$ \\
\hline $\mathrm{DE} 2$ & $\mathrm{~S}+\mathrm{T}($ winter $)+\mathrm{MWL}+\mathrm{Silt}+\mathrm{E}$ \\
\hline
\end{tabular}

${ }^{\S}$ Earthquake loading (Manjil)

Figure 21 shows non concurrent envelope of the maximum first principal stresses on upstream and downstream faces and figure 22 shows the envelope pertinent to the minimum third principal stresses for two considered seismic load combination. As it is clear, analysis of coupled system using NWL leads to higher tensile stresses in dam body. Maximum tensile stress experienced by dam body based on DE1 and DE2 load combinations are $14.6 \mathrm{MPa}$ and $12.7 \mathrm{MPa}$ respectively. Although in both cases high tensile stresses occur in upper parts of downstream face, its location shifts from central part in DE1 to left quarter part in DE2 load combination. In addition dam body experience 34.6MPa compressive stress in DE1 and only $12.8 \mathrm{MPa}$ under DE2 load combination. It's obvious that operating dam in MWL reduces compressive stress to about $1 / 3$ of NWL.

Figure 23 shows the cracked Gaussian points on upstream and downstream faces when the system is analyzed using DE1 load combination up to second 12.0. In present model cracking starts about $5^{\text {th }}$ second in downstream face and about $8^{\text {th }}$ second in upstream face. In the second about 7.5 blocks behave almost separately and in $10.6 \mathrm{~s}$ intensive drift is shown in crest of central cantilever that can leads to failure of upper part of central block as shown in figure 24. So considering un-convergence of system after $12 \mathrm{~s}$ of beginning of seismic load, fast extension of cracked area during earthquake, dramatic displacement in crest point and high potential for separation of part of central block leads to decide that dam is unsafe in DE1 load combination. 


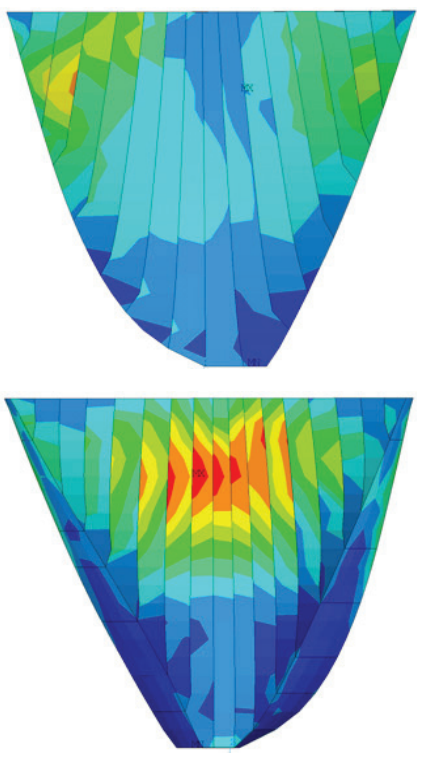

(a)

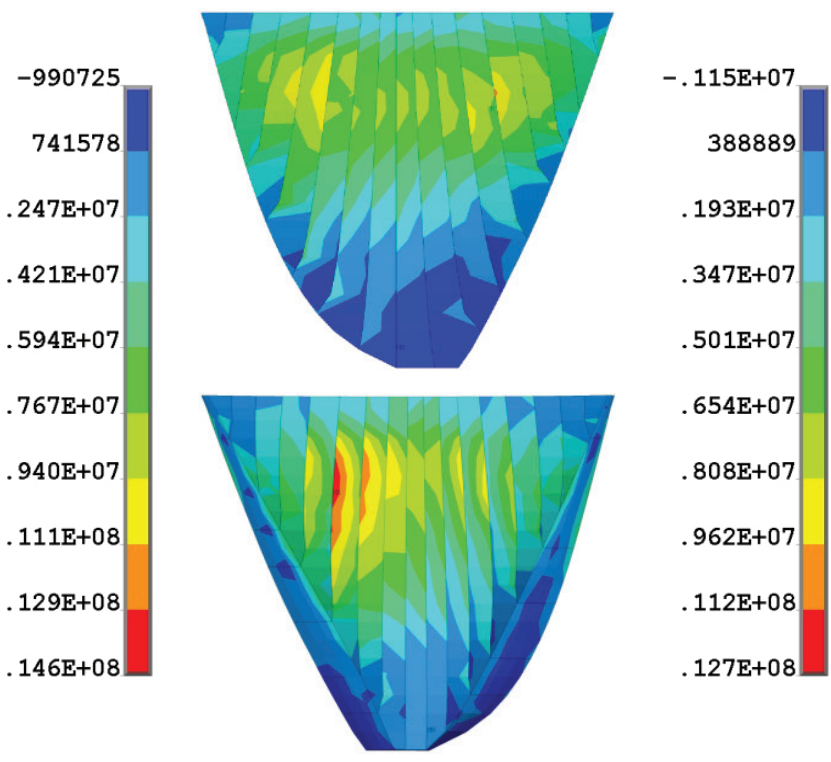

(b)

Fig. 21. Non-concurrent envelope of maximum first principal stress in upstream and downstream faces of dam body (Pa) in (a) DE1, (b) DE2.

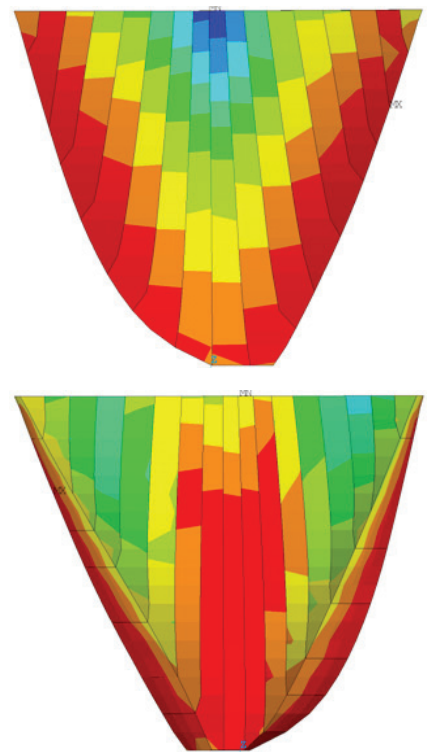

(a)
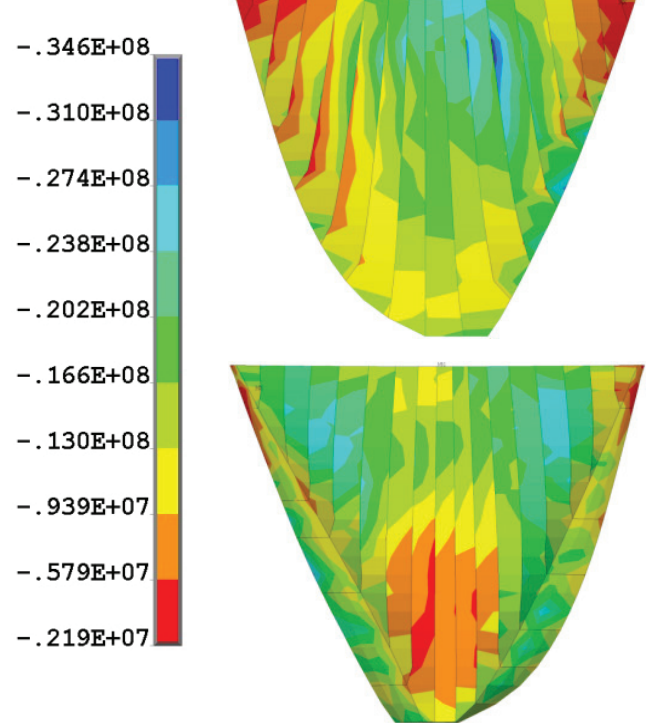

(b)

Fig. 22. Non-concurrent envelope of minimum third principal stress in upstream and downstream faces of dam body $(\mathrm{Pa})$ in (a) DE1, (b) DE2. 

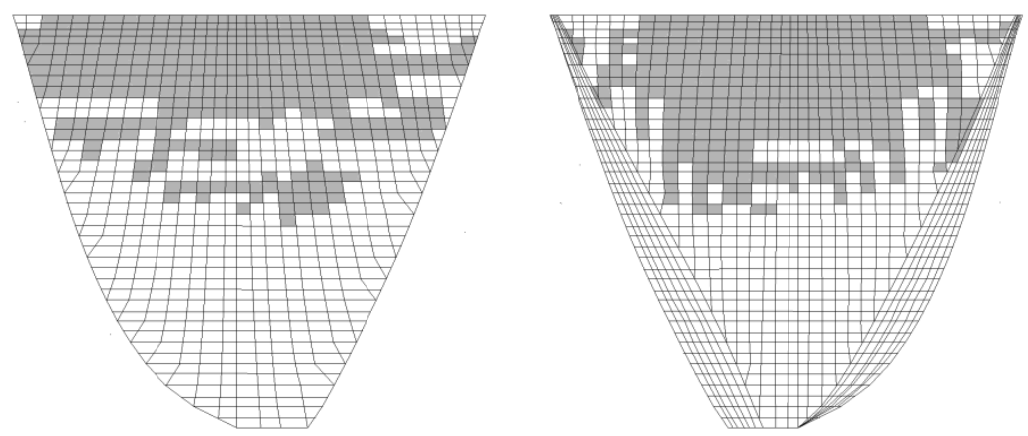

Fig. 23. Cracked Gaussian points on upstream and downstream faces; DE1 load combination .

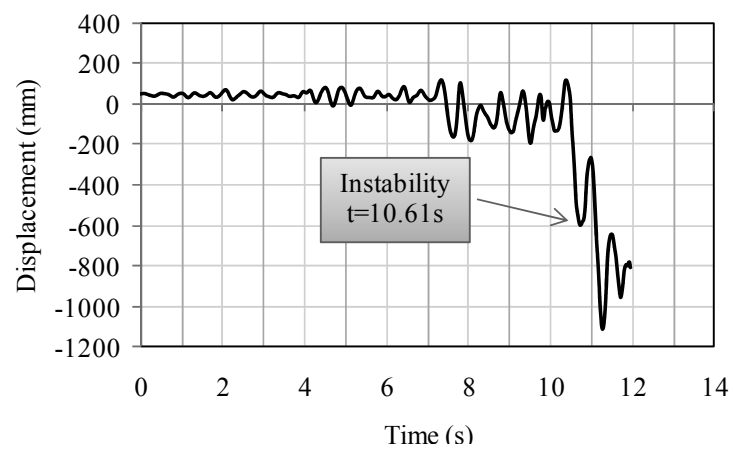

Fig. 24. Displacement time-history in crest of crown cantilever in stream direction up to un-convergence point.

Figure 25 shows cracked Gaussian points on upstream and downstream faces when the system is analyzed applying DE2 load combination. As can be seen in this load combination, cracked Gaussian points have meaningful reduction than to DE1 model. In this condition cracking is start in $t=4 \mathrm{~s}$ and spread in both faces up to $t=14 \mathrm{~s}$ and it has almost no change in rest of analysis. Finally figure 26 is shown time-history of crest point of crown cantilever in stream direction. Based on this figure, although a sudden change in displacement is shown about $t=7.5 \mathrm{~s}$, general trend of displacement variation for this point considering all nonlinearity models is acceptable and no separation between blocks or any hanging and instability is expected in this region. So it can conclude that dam is safe in this condition. 

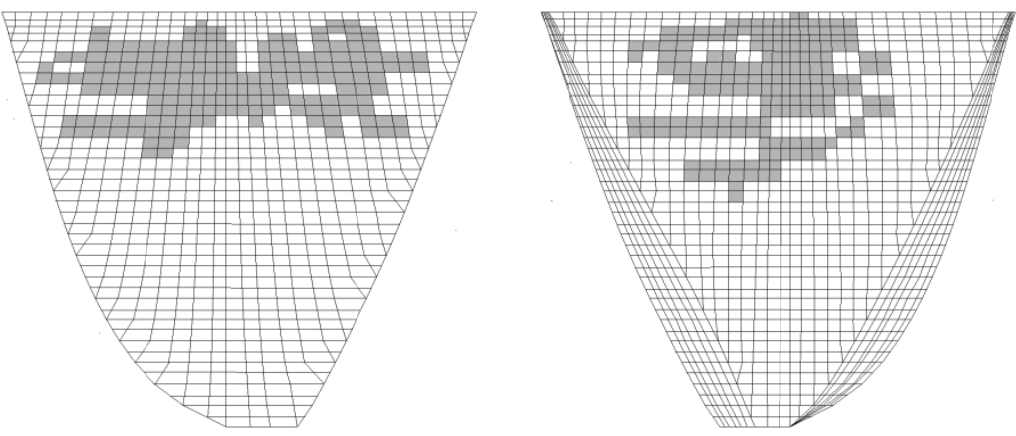

Fig. 25. Cracked Gaussian points on upstream and downstream faces; DE2 load combination.

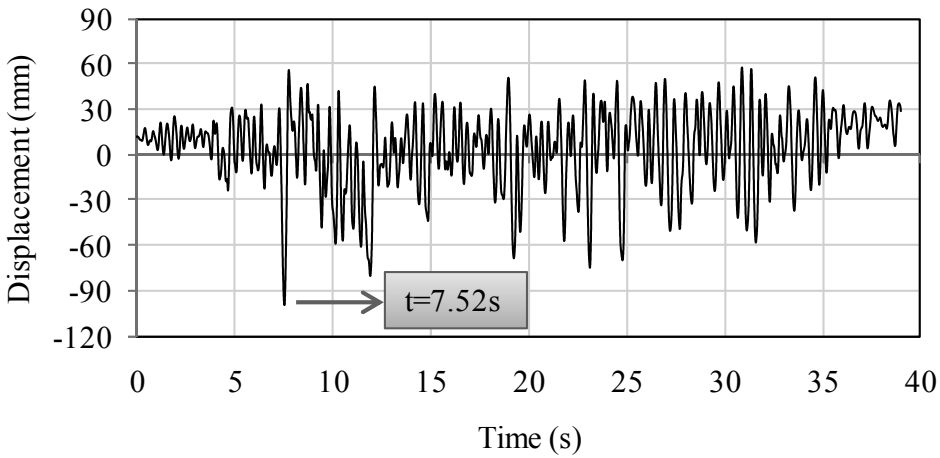

Fig. 26. Displacement time-history in crest of crown cantilever in stream direction for total time of seismic input based on DE2 load combination.

\section{Conclusion}

The numerical model of dam-reservoir-foundation coupled system was developed and calibrated based on field investigations and micro-geodesy data in both static and thermal conditions. Safety evaluation of dam was evaluated both under static and dynamic load combinations. Numerical model of material nonlinearity considering the effects of concrete cracking and crushing was taken into account. Also all joints were modeled using node-to-node contact elements in order to simulating the joint opening and sliding during seismic loading. Based on the results obtained from conducted dynamic analyses in MCE level, it is concluded that in NWL there is block instability and the existing dam is not safe enough while in MWL there is not any numerical or block instability. 


\section{REFERENCES}

1. G. Mazż̀, A. Marcello, R. Ceruti, Safety reassessment of multiple arch dams in Italy: General considerations and presentation of a case-study, International Congress on Conservation and Rehabilitation of Dams, 11-13 Nov, 2002, Madrid, Spain.

2. Behan-sad Engineering and consulting Co., Seismic hazard analysis of DEZ dam, 2009, Tehran, Iran.

3. Water and power ministry, Design and analysis of DEZ dam, 1963, Tehran, Iran.

4. G. Lombardi, and M. Fanelli, On the Lombardi slenderness coefficient for assessing cracking potential of arch dams, Proceeding of International Symposium on Arch Dams, China, 1992.

5. Federal Energy Regulatory Commission (FERC), Engineering guideline for the evaluation of hydropower projects-chapter 11: Arch dam design; Federal Energy Regulatory Commission Division of dam safety inspection, 1999.

6. H. Mirzabozorg, and M. Ghaemian, Nonlinear seismic analysis of dam including dam-reservoir interaction (NSAD-DRI) user manual, 2002.

7. F. Sheibany, M. Ghaemian, Effects of environmental action on thermal stress analysis of Karaj concrete arch dam”, ASCE, J. Eng. Mech., 132(5), 532-545, 2006.

8. Z. Bofang, Prediction of Water Temperature in Deep Reservoir, Dam Engineering, VIII (1), 1997.

9. EM 1110-2-6053: Earthquake Design and Evaluation of Concrete Hydraulic Structures, U. S. Army Corps of Engineering (USACE), Washington D.C., 2007.

10. H. Kupfer, H.K. Hilsdorf, H. Rusch, Behavior of concrete under biaxial stresses, ACI Journal, 656-666, 1969.

11. ICOLD, Selecting Seismic Parameters for Large Dams, ICOLD Bulletin, 72, 1989.

Received: 13.12 .2012

Revised: 27.02 .2013 